\title{
Transcriptomic and genomic evidence for Streptococcus agalactiae adaptation to the bovine environment
}

Vincent P Richards ${ }^{1}$, Sang Chul Choi ${ }^{2,3}$, Paulina D Pavinski Bitar ${ }^{1}$, Abhijit A Gurjar ${ }^{1,4}$ and Michael J Stanhope ${ }^{1 *}$

\begin{abstract}
Background: Streptococcus agalactiae is a major cause of bovine mastitis, which is the dominant health disorder affecting milk production within the dairy industry and is responsible for substantial financial losses to the industry worldwide. However, there is considerable evidence for host adaptation (ecotypes) within S. agalactiae, with both bovine and human sourced isolates showing a high degree of distinctiveness, suggesting differing ability to cause mastitis. Here, we (i) generate RNAseq data from three S. agalactiae isolates (two putative bovine adapted and one human) and (ii) compare publicly available whole genome shotgun sequence data from an additional 202 isolates, obtained from six host species, to elucidate possible genetic factors/adaptations likely important for S. agalactiae growth and survival in the bovine mammary gland.

Results: Tests for differential expression showed distinct expression profiles for the three isolates when grown in bovine milk. A key finding for the two putatively bovine adapted isolates was the up regulation of a lactose metabolism operon (Lac.2) that was strongly correlated with the bovine environment (all 36 bovine sourced isolates on GenBank possessed the operon, in contrast to only 8/151 human sourced isolates). Multi locus sequence typing of all genome sequences and phylogenetic analysis using conserved operon genes from 44 S. agalactiae isolates and 16 additional Streptococcus species provided strong evidence for acquisition of the operon via multiple lateral gene transfer events, with all Streptococcus species known to be major causes of mastitis, identified as possible donors. Furthermore, lactose fermentation tests were only positive for isolates possessing Lac.2. Combined, these findings suggest that lactose metabolism is likely an important adaptation to the bovine environment. Additional up regulation in the bovine adapted isolates included genes involved in copper homeostasis, metabolism of purine, pyrimidine, glycerol and glucose, and possibly aminoglycoside antibiotic resistance.
\end{abstract}

Conclusion: We detected several genetic factors likely important in S. agalactiae's adaptation to the bovine environment, in particular lactose metabolism. Of concern is the up regulation of a putative antibiotic resistance gene (GCN5-related N-acetyltransferase) that might reflect an adaptation to the use of aminoglycoside antibiotics within this environment.

Keywords: Streptococcus agalactiae, Bovine adapted, RNAseq, Lactose operon, Lateral gene transfer, Mastitis, Differential gene expression

\footnotetext{
* Correspondence: mjs297@cornell.edu

${ }^{1}$ Department of Population Medicine and Diagnostic Sciences, College of

Veterinary Medicine, Cornell University, Ithaca, NY 14853, USA

Full list of author information is available at the end of the article
} 


\section{Background}

In addition to causing severe invasive infections in adults and neonates (e.g. pneumonia, meningitis, and septicemia) [1-3], Streptococcus agalactiae (Group B Streptococcus; GBS) is a major cause of bovine mastitis $[4,5]$, which is the dominant health disorder affecting milk production in the dairy industry, and is responsible for significant financial losses worldwide [6-11]. S. agalactiae has been isolated from a diversity of vertebrate hosts ranging from humans to crocodiles and fish [12-14], and there is considerable evidence for host adaptation among strains, with both human and bovine sourced isolates showing a high degree of genetic distinctiveness [15-20]. Therefore, the objectives of this study were to (i) assess how the genomic gene expression of bovine sourced S. agalactiae (putative bovine adapted) responded to growth in bovine milk when compared to human sourced S. agalactiae, and (ii) place our findings into a wider context via comparison of over 200 additional $S$. agalactiae genome sequences obtained from a variety of host species.

A principle now generally regarded as common to most or all bacteria is that of the pan-genome, which is comprised of both a set of core and dispensable genes, with only the former present in all isolates of that species [21]. There is now abundant evidence to support the view that the dispensable genes are fundamental to adaptive and phenotypic differences between strains [20,22-28]. Earlier genomic studies of $S$. agalactiae gene expression used microarrays and did not focus on potential ecotypic adaptation. [29-33]. Here we present the first comparative transcriptomic study of $S$. agalactiae based on RNAseq data. The comparison involves three S. agalactiae strains representing distinct ecotypes to elucidate possible genetic factors/adaptations likely important for S. agalactiae growth and survival in the bovine mammary gland. Our findings reveal several genetic factors likely important in S. agalactiae's adaptation to the bovine environment, in particular, genes involved in carbohydrate metabolism.

\section{Methods}

\section{Strain selection}

The putative bovine adapted $S$. agalactiae strain used in this study (FSL S3-586) was obtained from a quarter milk sample isolated from a cow with mastitis in Wayne County, NY, USA [18]. The strain was isolated in 2001 and is MLST sequence type (ST) 67. ST-67 has been frequently isolated from cows suffering with mastitis [15]. The human sourced strain (CCUG 37738) was isolated from the blood of a female newborn with sepsis in Göteborg, Sweden (1994). The strain was determined here to be ST-19 using its genome sequence (GenBank accession number: ALQP01000000). ST-19 has been frequently isolated from human sources [15,34-36]. S. agalactiae strains from the ST-23 lineage have possibly the widest host range. Strains have been isolated from humans, cattle, dogs, crocodiles, and grey seals, with the ST showing high frequency in both human and bovine environments [5,12,13,15,34-36]. Given that strains from this lineage might be adapted to both human and bovine environments, we also included a strain with this ST in our analysis. We selected strain NEM316, as this strain has been included in numerous previous studies (including whole-genome transcriptome analysis) and its genome has been sequenced $[12,15,29,32,35,37-39]$. While the strain has been described in the literature as being a human isolate, Sørensen et al. [35] showed its isolation source to be unknown.

No experimental research on vertebrates or any regulated invertebrates was performed. Compliance with the ARRIVE (Animal Research: Reporting In Vivo Experiments) guidelines is not applicable.

\section{Bacteria culturing}

All strains were grown, in triplicate, in untreated bovine milk and Todd Hewitt Broth with 0.5\% yeast extract (THY) at $37^{\circ} \mathrm{C}$ and normal atmospheric conditions. Bovine milk with low somatic cell count $(<200,000$ cells $/ \mathrm{mL})$ was collected and pooled from four cows (seven quarters total), approximately 30 minutes prior to inoculation. Overnight cultures of the strains were used to inoculate the milk and THY media to 1:100 dilution (500 $\mu \mathrm{L}$ overnight culture in $50 \mathrm{~mL}$ media). Cultures were grown to mid-exponential phase and harvested.

Growth curve measurements for each strain were obtained using the drop plate method [40]. For each onehour time point, serial dilutions were made (in PBS $\mathrm{pH}$ 7.4) and plated (five drops of $10 \mu \mathrm{L}$ in duplicate for each of four to six dilutions) on TSAII with $0.5 \%$ sheep blood and incubated overnight. After 24 hours, colonies were counted and $\mathrm{CFU} / \mu \mathrm{L}$ was calculated. Drops were considered countable if they contained 3-30 colonies. Standard error for each pair of replicates at each time point was calculated (for some time points, only one drop was countable, precluding standard error calculation).

\section{Lactose fermentation}

Strains were grown at $37^{\circ} \mathrm{C}$ in $7 \mathrm{~mL}$ Phenol Red Broth Base with Meat Extract (HiMedia) supplemented with $1 \%$ lactose (BD Difco). After 7 days the color of the media was noted. The media changed color to either yellow or orange. Two $\mathrm{pH}$ measurements were taken for each. For yellow the average $\mathrm{pH}$ was 4.6, for orange the average $\mathrm{pH}$ was 6.5 . A color change to yellow was taken as an indication of lactose fermentation. 


\section{RNA extraction, cDNA library construction, and sequencing}

Milk cultures at mid-exponential phase were centrifuged at $3,500 \mathrm{rpm}$ and $4^{\circ} \mathrm{C}$ for 30 minutes to pellet the bacteria. Whey and fat were removed and the pellet resuspended in $9.0 \mathrm{~mL}$ of 1:2 mix of phosphate buffered saline (PBS) and RNAprotect (Qiagen). The solution was filtered through a five-micron filter to remove intact bovine cells while leaving behind $S$. agalactiae cells (size $\leq 1$ micron). Cells were centrifuged at $5000 \mathrm{rpm}$ for 10 minutes, supernatant removed, and the pellet frozen at $-80^{\circ} \mathrm{C}$. THY cultures at mid-exponential phase were centrifuged at $3,500 \mathrm{rpm}$ and $4^{\circ} \mathrm{C}$ for 30 minutes to pellet the bacteria. The pellet was re-suspended in $1.0 \mathrm{~mL}$ RNAprotect. Following a second centrifugation at 5,000 rpm for 10 minutes, the supernatant was removed and the pellet frozen at $-80^{\circ} \mathrm{C}$. All pellets were re-suspended in $280 \mu \mathrm{L}$ of $\mathrm{TE}$ and combined with $300 \mu \mathrm{L}$ of acidic phenol:choloroform (Ambion) and $250 \mu \mathrm{L}$ of $0.1 \mathrm{~mm}$ glass beads (BioSpec Products). Cells were mechanically disrupted and centrifuged at 13,200 rpm for 10 minutes to separate them. $200 \mu \mathrm{L}$ of the supernatant was combined with $700 \mu \mathrm{L}$ Qiagen RLT buffer containing $7 \mu \mathrm{L} \quad \beta$-mercaptoethanol, and transferred to a Qiagen RNeasy Mini kit column. The extraction was completed following the Qiagen protocol, which included an on-thecolumn DNAse digest (Qiagen). Trace mammalian RNA was removed from extracted RNA samples using the MICROBEnrich $^{\mathrm{TM}}$ Kit (Ambion). Samples were depleted of rRNA using the MICROBExpress ${ }^{\mathrm{TM}}$ Bacterial mRNA Enrichment Kit. cDNA libraries were constructed using the TruSeq RNA Sample Prep Kit (Illumina) and sequenced using Illumina Hiseq 2000 (100 bp reads, single end) (six samples/lane). Two separate replicates (one each for strains FSL S3-586 and NEM316) grown in broth were excluded from sequencing due to suspected cross contamination. Summary sequencing statistics are shown in Table 1.

\section{Differential gene expression, functional annotation, and clustering}

Adaptor sequences were removed from Illumina reads using cutadapt [41]. Reads for each strain were then mapped to respective genome sequences using BWA [42]. Genome sequences were obtained from GenBank (FSL S3-586: ANCM01000000, CCUG 37738: ALQP01000000, NEM316: NC_004368). Short read alignments were converted to readable formats using SAMtools [43], and the number of reads aligned to annotated genes was counted using R [44]. Significant differences in expression between growth in milk and broth were determined using DEseq [45]. The false discovery rate (FDR) procedure of Benjamini and Hochberg [46] was used to correct for multiple hypothesis testing $(F D R=0.05)$. Gene Ontology (GO) terms were assigned to genes showing significant
Table 1 Summary Illumina sequencing statistics

\begin{tabular}{lllll}
\hline Strain & $\begin{array}{l}\text { Growth } \\
\text { environment }\end{array}$ & $\begin{array}{l}\text { Replicate } \\
\text { of reads }\end{array}$ & $\begin{array}{l}\text { Total number } \\
\text { aligned reads }\end{array}$ \\
\hline NEM316 & Milk & 1 & $29,089,124$ & $27,350,545$ \\
NEM316 & Milk & 2 & $40,554,665$ & $38,161,713$ \\
NEM316 & Milk & 3 & $35,497,113$ & $33,357,550$ \\
NEM316 & Broth & 1 & $23,013,312$ & $21,250,407$ \\
NEM316 & Broth & 2 & $23,145,072$ & $21,484,496$ \\
CCUG & Milk & 1 & $20,106,316$ & $7,516,242$ \\
37738 & & & & \\
CCUG & Milk & 2 & $16,800,749$ & $6,494,892$ \\
37738 & & & & \\
CCUG & Milk & 3 & $28,308,724$ & $11,028,696$ \\
37738 & & & & \\
CCUG & Broth & 1 & $44,274,054$ & $19,357,826$ \\
37738 & & & & \\
CCUG & Broth & 2 & $27,893,761$ & $11,196,100$ \\
37738 & & & & \\
CCUG & Broth & 3 & $17,763,818$ & $7,925,653$ \\
37738 & & & & \\
FSL S3-586 & Milk & 1 & $29,138,705$ & $8,033,022$ \\
FSL S3-586 & Milk & 2 & $27,373,266$ & $4,909,064$ \\
FSL S3-586 & Milk & 3 & $16,688,288$ & $6,786,044$ \\
FSL S3-586 & Broth & 1 & $15,172,203$ & $4,505,824$ \\
FSL S3-586 & Broth & 2 & $21,093,103$ & $6,750,884$ \\
\hline The & 2 & & & \\
\hline
\end{tabular}

The average proportion of reads passing the Illumina quality filter for each replicate was $94.6 \%$ (range $=93-97 \%$ ). The number of aligned reads excludes reads ambiguously aligned to multiple locations within the respective genome sequence.

differential expression using Blast2GO v.2.5.0 [47]. These genes were also assigned GO-Slim terms using the generic GO Slim (http://www.geneontology.org/GO_slims/goslim_generic.obo). GO Slim is a reduced version of the full GO that contains a sub-set of more general GO terms and excludes the more fine-grained specific terms. This approach provides a broad overview of the ontology and gene product function for genomic data.

Genes for all three strains were delineated into homologous clusters using the MCL algorithm [48] as implemented in the MCLBLASTLINE pipeline (available at http://micans.org/mcl). The pipeline uses Markov clustering (MCL) to assign genes to homologous clusters based on a BLASTp search between all pairs of protein sequences using an $E$ value cut-off of $1 \mathrm{e}-5$. The MCL algorithm was implemented using an inflation parameter of 1.8. Simulations have shown this value to be generally robust to false positives and negatives [49].

\section{Phylogenetic analysis}

The lacGEFDCBA genes from the Lac.2 operon (see Results and Discussion) for 60 Streptococcus strains (17 species) (Additional file 1) were aligned using MAFFT v6.814b [50] as implemented in Geneious v5.5.3 [51]. A 
Maximum Likelihood phylogeny with 500 bootstrap replicates was constructed using PhyML v3.0 [52] and the GTR + I + G substitution model, which was determined as the best fit for the data using Modeltest v3.7 [53].

\section{Results and discussion Differential gene expression}

The human isolate showed considerably more differential expression when grown in bovine milk than the other two strains. Specifically, 305, 34, and 48 genes for the human isolate, bovine isolate, and NEM316 showed significantly more expression in bovine milk when compared to broth (up regulation) (see Additional file 2). This represents $14.4 \%, 1.4 \%$, and $2.3 \%$ of the total number of genes in each genome respectively. The isolates had similar numbers of genes with less expression in milk relative to broth (down regulated): human $=298$ $(14.0 \%)$, bovine $=43(1.8 \%)$, and NEM316 = 25 (1.2\%).

The number of genes up regulated was not correlated with growth. For example, in milk, final CFUs/ $\mu \mathrm{L}$ were highest for NEM316, followed by the bovine isolate, and lastly the human isolate, with NEM316 showing considerably more growth than the other two isolates (Figure 1). In broth, the isolates showed less variation in growth. Nevertheless, NEM316 again showed the highest growth, with the other two strains showing approximately equal growth. Both NEM316 and the bovine isolate showed higher growth in milk compared to broth. However, the difference was far more pronounced for NEM316. Conversely, the human isolate showed more growth in broth than milk. Combined,

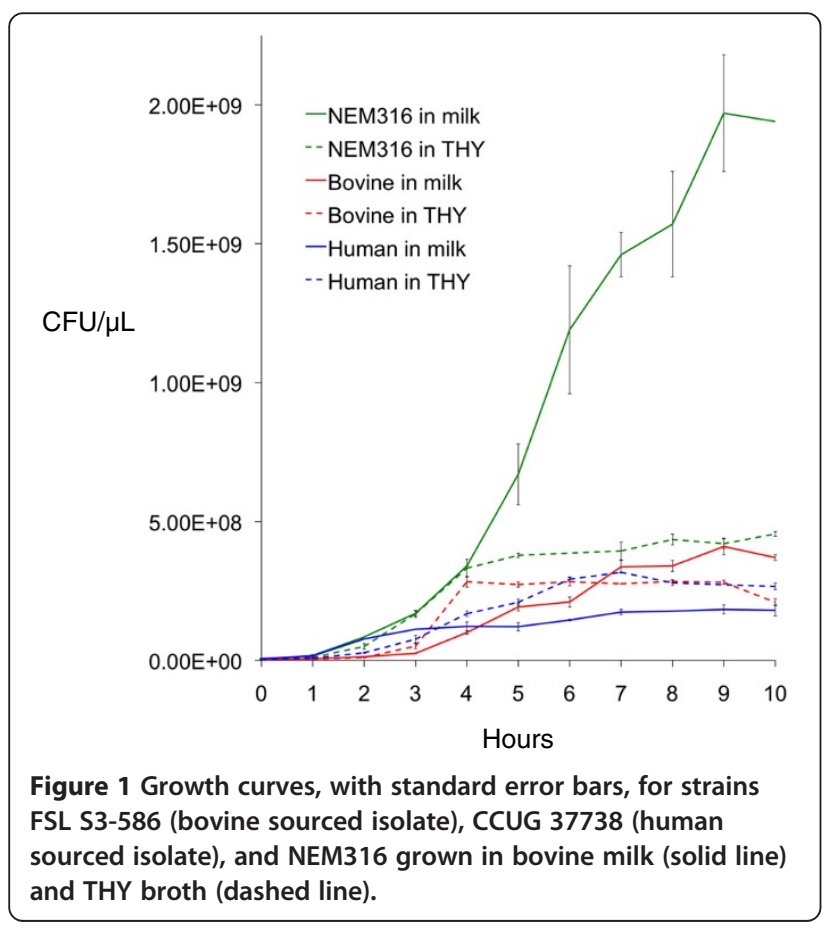

these observations suggest that NEM316 and the bovine isolate are better adapted to the bovine environment than the human isolate.

Figures 2 and 3 show the proportion of each of the GO Slim terms that were assigned to the genes showing differential expression. Proportions are relative to the total number of terms assigned (genes can be assigned multiple GO terms). Therefore, the chart shows the proportional distribution of functional categories for the genes differentially expressed for each isolate. The right side of the chart shows proportions for terms assigned to genes that were up regulated, whereas the left side shows proportions for genes that were down regulated. For each term, Fisher exact tests comparing the number of up regulated genes to the number of down regulated genes detected no significant differences for the bovine isolate or NEM316 (FDR correction of 0.05). However, tests for the human isolate detected 33 terms that were significantly underrepresented for up regulated genes and one term that was over represented (Figures 2 and 3 ). Of these terms, 16 were for biological processes, 15 were for cellular component, and three were for molecular function. For the biological processes terms, metabolic and biosynthesis processes were the most frequent. For example, there were eight terms associated with metabolic processes and five terms associated with biosynthesis processes. The remaining three terms were for translation, gene expression, and generation of precursor metabolites and energy. These findings suggest a significant reduction in metabolic activity for the human isolate when grown in bovine milk.

The human isolate was also distinctive regarding genes involved in response to stress. Specifically, the following four genes were up regulated: a CSD family cold shock protein (SAG0061_02621), a universal stress family protein (SAG0061_03696), a heat shock protein GrpE (SAG0061_10653), and a heat-inducible transcription repressor (SAG0061_10658). The isolate showed a similar stress response to growth in broth, with the following three stress response genes showing up regulation: a universal stress family protein (SAG0061_03421), a heat shock protein HtpX (SAG0061_03931), and a molecular chaperone DnaK SAG0061_10648. In contrast, the bovine isolate showed no up regulation for stress response genes in either environment and NEM316 showed up regulation for just one gene when grown in milk: a cold shock protein (gbs2053). Concordant with the growth patterns in milk, these results also suggest that the bovine isolate and NEM316 are better adapted to the bovine environment than the human isolate. However, while these results also suggest that the bovine isolate and NEM316 are better adapted to the broth environment than the human strain, this was not entirely reflected by the growth patterns in broth as the bovine 


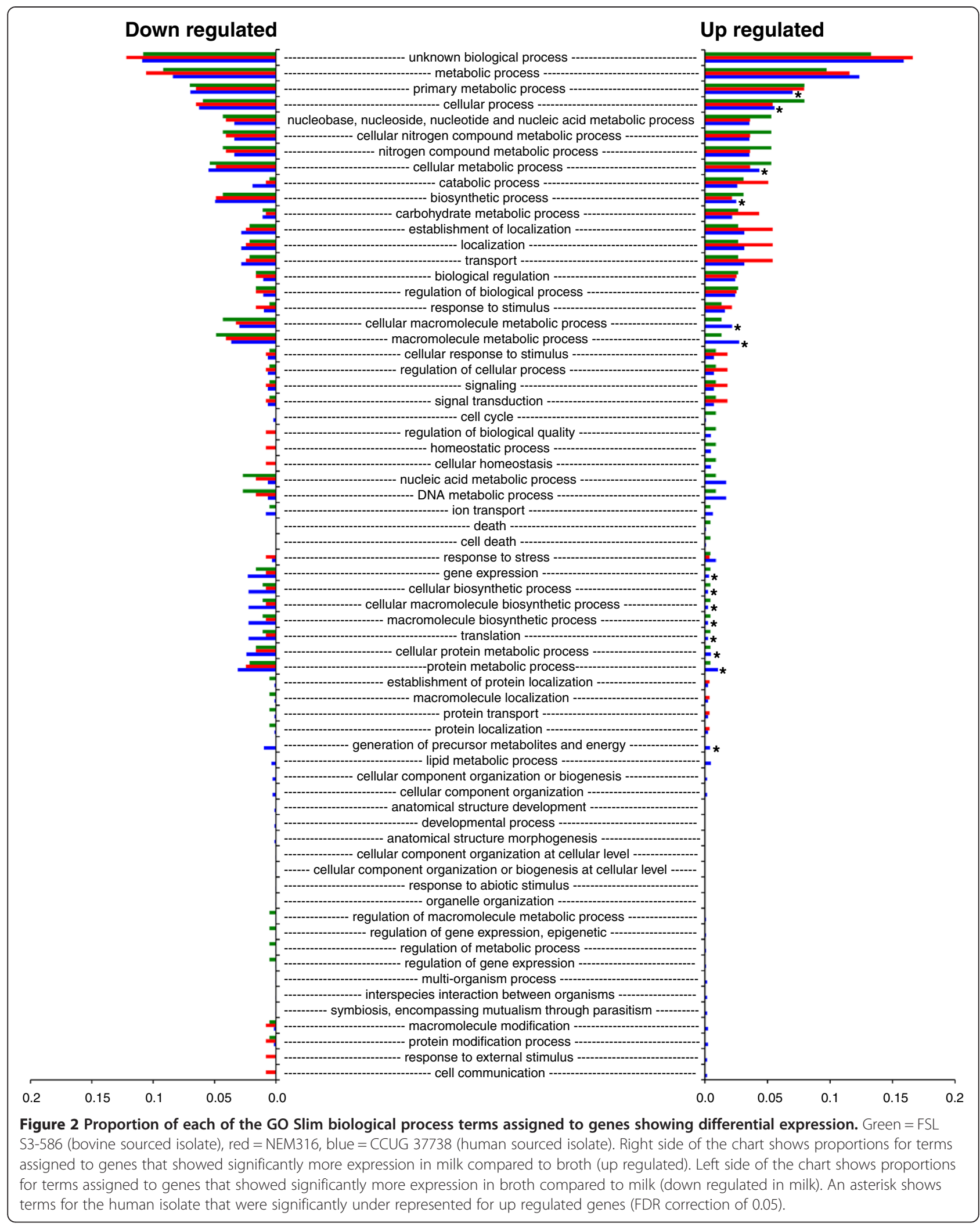




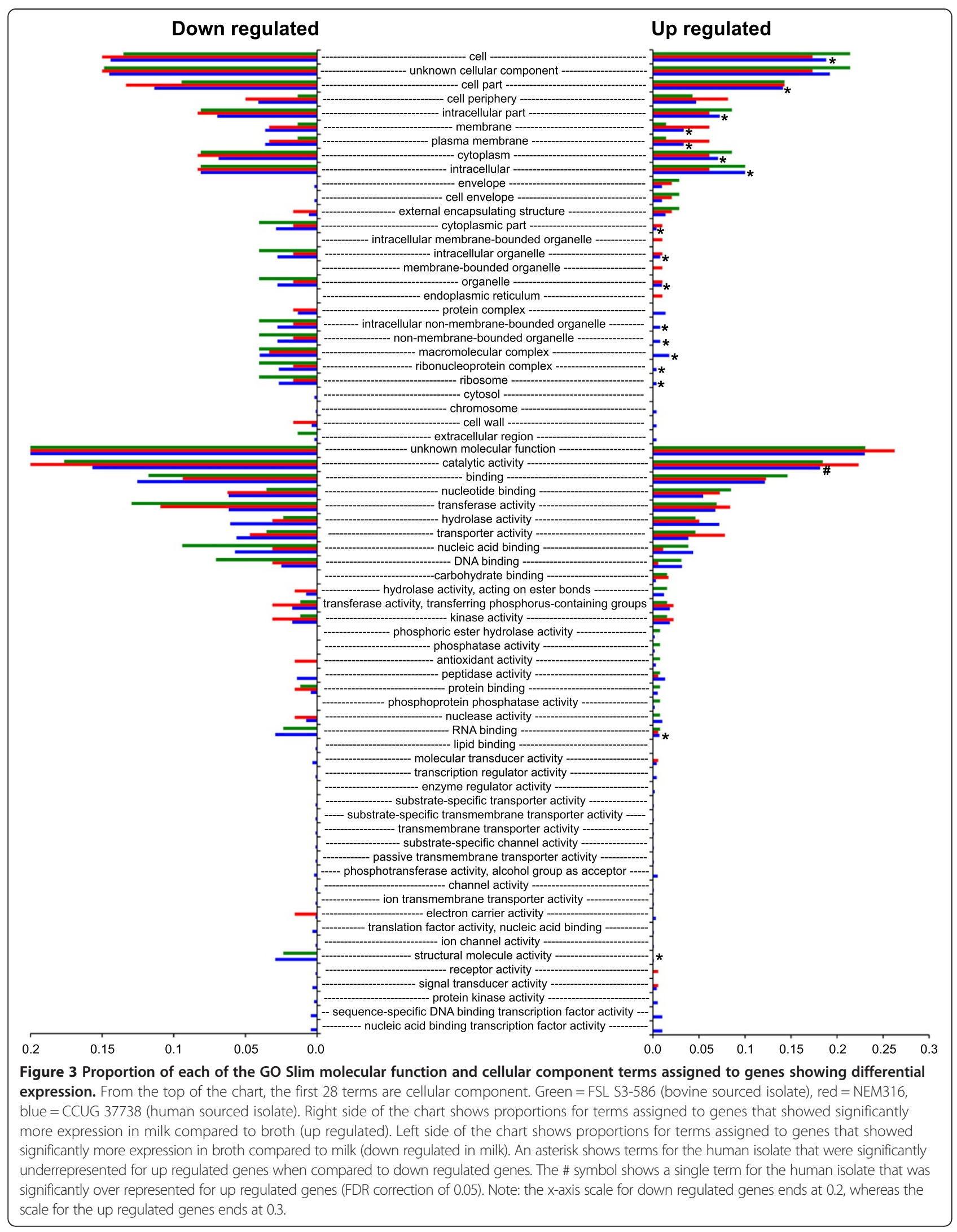


and human isolates showed similar growth in this environment. In other words, despite the human isolate's strong stress response in broth, it was still able to grow as well as the bovine isolate in this environment.

Interestingly, strain NEM316 does not appear as welladapted to human blood as it does to milk. For example, Mereghetti et al. [29] reported that after 90 minutes growth at $37^{\circ} \mathrm{C}$ and $40^{\circ} \mathrm{C}$ the following stress response genes were up regulated: a universal stress family protein (gbs1721), two general stress proteins (gbs1202 and gbs1204), a chaperone (gbs0625), a ClpL protease (gbs1376gbs), and a stress response regulator (gbs0756). Conversely, NEM316 might be as equally well adapted to human amniotic fluid, as it appeared to be to milk, as Sitkiewicz et al. [32] reported that it showed down regulation for all stress response genes when grown in this environment (with the exception of one gene [gbs2029-chaperonin GroEL] that showed moderate up regulation).

\section{Lactose operon}

Both the bovine isolate and NEM316 showed up regulation for a shared eight or nine gene operon that has been shown to be involved in the transport and metabolism of lactose [54] (Figure 4). The operon corresponds to what is referred to as Lac.2 [55] and utilizes the phosphoenolpyruvate (PEP)-dependant sugar-phosphotransferase system (PTS). With one exception, the clustering analysis showed all genes in the operon for each of the two isolates to be homologous. The exception was NEM316, which possessed an additional gene: lacT. Another difference between the two operons was that $l a c R$ for the bovine isolate was orientated in the opposite direction to the remainder of the operon. Gene order for the operon was as follows: lacRABCDFEGX (bovine isolate),
lacRABCDTFEGX (NEM316). Both lacR and lacT may have regulatory functions. For example, lacR is a putative negative regulator of the operon that likely functions by binding to the promoter in the absence of lactose $[54,56,57]$, and in contrast to the remainder of the operon, this gene was not up regulated. lacT is an antiterminator, which may function to regulate downstream expression of lacFEGX. For Lactobacillis casei, the lacT gene product is believed to bind to a ribonucleic antiterminator (RAT) motif within an mRNA secondary structure that prevents the formation of a rho-independent terminator stem-loop structure that would otherwise terminate downstream transcription [58]. For NEM316, lacT was up regulated and a search of the upstream $392 \mathrm{bp}$ intergenic region using the ARNold webserver (http://rna.igmors.u-psud.fr/toolbox) detected a putative $65 \mathrm{bp}$ rho-independent terminator motif with a stem-loop free energy of $-8.26 \mathrm{kcal} / \mathrm{mol}$. In addition, a putative -10 promoter consensus sequence (TATAAT) was detected starting 98 bp upstream of the start of the terminator. Although we could not detect a motif resembling the proposed RAT consensus sequence of Brown and Thompson [59], previously detected in Streptococcus mutans [60], we did detect a 35 bp imperfect inverted repeat that was 100 bp upstream of the rhoindependent terminator that might function as a RAT.

While both the putatively bovine adapted isolates possessed Lac.2, the human isolate lacked it, and previous examination of genome sequences for seven human sourced isolates and one bovine sourced isolate also showed that Lac. 2 was only present in the bovine sourced isolate [20]. Here we used BLASTn ( $E$ value cut-off of 1e-5) to survey an additional 202 S. agalactiae genome sequences available on GenBank (see Additional

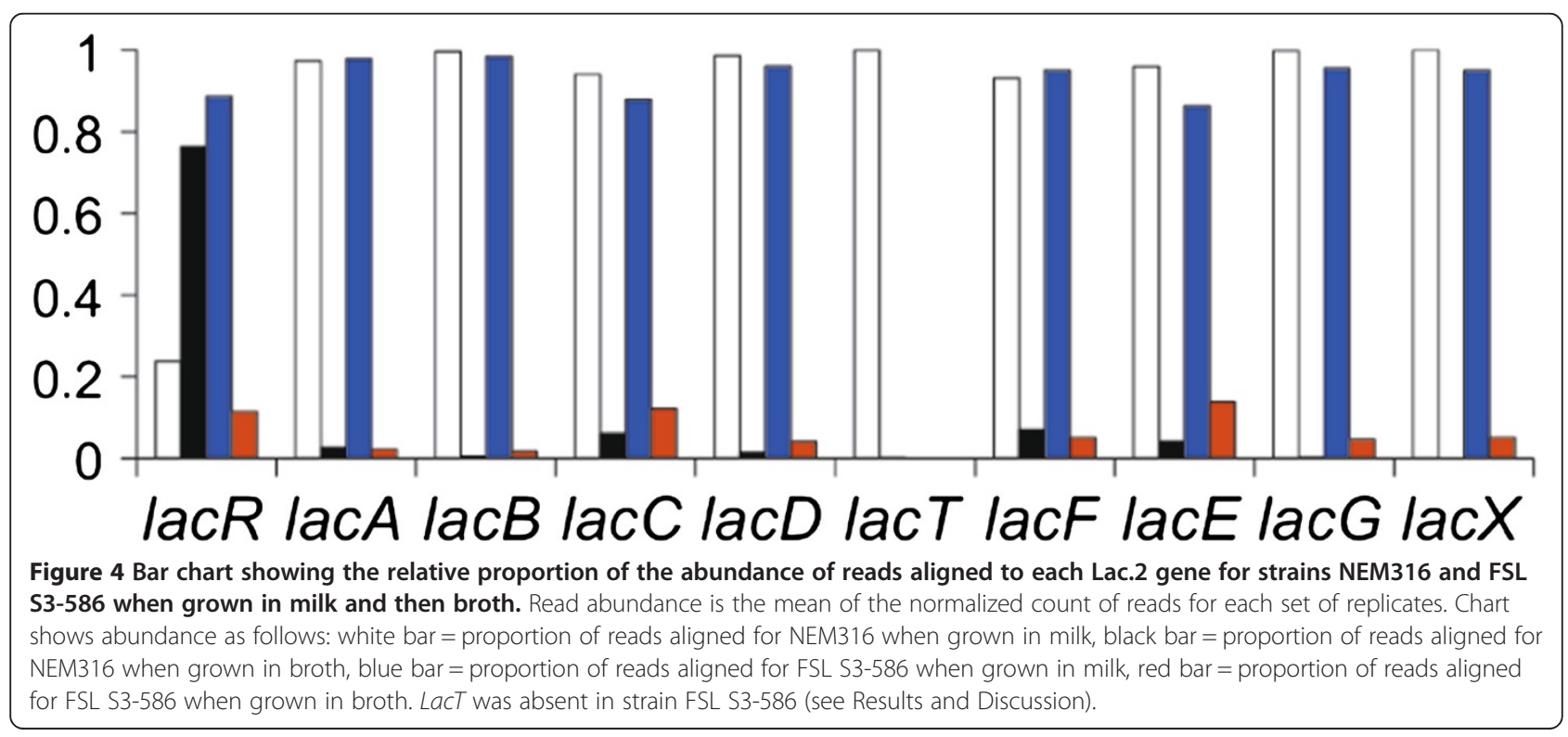


file 1) for the presence of Lac.2. These strains were isolated from a range of vertebrate hosts: human $=151$, bovine $=35$, tilapia $=13$, dolphin $=1$, bullfrog $=1$, and grey seal $=1$. Lac. 2 was present in 42 isolates. This included all 35 bovine sourced isolates and seven human sourced isolates. Again using BLASTn, we determined the MLST ST for each isolate (including the bovine and human isolates analyzed using RNAseq data). All of these genome sequences were WGS, and as a consequence, MLST alleles were occasionally truncated. Therefore, we were unable to determine allele profiles for 21 isolates. Of the seven human sourced isolates that possessed Lac.2, three were ST-88, two were undetermined, and the remaining two were ST-25 and ST-103. ST-88 and ST-25 belong to clonal complex 23, which also includes ST-23 (NEM316). These results clearly show a very strong correlation between Lac. 2 and the bovine environment (all bovine sourced isolates possessed the operon).

We identified 17 different STs for the bovine isolates (Additional file 1) and previous studies have shown these STs to not cluster together in phylogentic analyses $[35,61]$. Furthermore, there were numerous examples where the possession of Lac. 2 was not conserved for all isolates of the same ST. For example, ST-1 occurred 19 times, yet only three of the isolates with this ST possessed Lac.2 (Additional file 1). Other examples were ST-23 ( $\mathrm{n}=16$, Lac. $=1)$, ST-7 $(\mathrm{n}=9$, Lac. $2=1)$, ST-88 $(\mathrm{n}=6$, Lac. $2=3)$, and ST-2 $(\mathrm{n}=5$, Lac. $2=1)$. Combined, these findings strongly suggest that acquisition of Lac. 2 was via lateral gene transfer (LGT) rather than vertical inheritance. LGT of this operon is further supported by previous work showing that Lac. 2 was likely exchanged between a bovine sourced isolate of $S$. agalactiae and another mastitis causing pathogen Streptococcus dysgalactiae subsp. dysgalactiae via an integrative conjugative element (ICE) [20]. Furthermore, Lac.2 is also within an ICE for NEM316 and another species of Streptococcus (Streptococcus canis - FSL S3-227) [62]. Strain FSL S3227 was isolated from a cow with an intra-mammary infection that belonged to a dairy herd experiencing an outbreak of S. canis induced mastitis [63].

\section{Evolution of Lac.2}

We further explored the evolutionary history of Lac. 2 by aligning the operon from each $S$. agalactiae isolate to 16 additional Streptococcus species representing a range of phylogenetic groups (mitis, sanguinis, mutans, pyogenic, and bovis) and then constructed a maximum likelihood phylogeny (see Methods, Figure 5, and Additional file 1). The genes lacX, lacT, and lacR were not consistently present in all isolates nor species and were therefore excluded from the analysis. Within the phylogeny, the Lac.2 sequences for $S$. agalactiae formed four major groupings (A, B, C, and D) that were strongly supported.
Three (B, C, and D) clustered together, while the fourth (A), which contained NEM316, was very distantly related (10 of the additional Streptococcus species separated them). As described above, S. agalactiae isolates possessed one of two different types of Lac. 2 operon. Here we designate them Lac.2-1 (lacT present and lacR orientated in the same direction as the remainder of the operon) and Lac.2-2 (lacT missing and lacR orientated in the opposite direction). Four isolates within group D lacked lacR (Additional file 1 and Figure 5). When the two types of Lac. 2 were overlain on the phylogeny, they clustered separately, with groups A, B, and C exclusively containing Lac.2-1 and group D exclusively containing Lac.2-2, suggesting distinct evolutionary histories for the Lac. 2 types. Four of the additional Streptococcus species fell within group D (S. dysgalactiae subsp. dysgalactiae, Streptococcus pyogenes, Streptococcus parauberis, and Streptococcus urinalis) and two within group C (Streptococcus dysgalactiae subsp. equisimilis and Streptococcus uberis). The close relationship between these additional species and the S. agalactiae group they fell within, compared to the much larger evolutionary distance among the $S$. agalactiae groups lends further support for the lateral exchange of Lac. 2 between $S$. agalactiae and other Streptococcus species. It's noteworthy that S. dysgalactiae subsp. dysgalactiae, S. uberis, and S. parauberis are major causes of mastitis and were all isolated from the bovine environment, suggesting this exchange may have occurred within this environment. However, three additional Streptococcus species, all isolated from the human environment, also fell within groups C (S. dysgalactiae subsp. equisimilis) and D (S. pyogenes and $S$. urinalis), raising the possibility that exchange may have also occurred in the human environment. One S. agalactiae strain (LMG 14838) was particularly interesting, as it possessed both types of Lac.2, with the phylogeny showing them to be highly divergent, likely reflecting acquisition of the operon on separate occasions from different species. None of the additional species included in the phylogeny fell within groups A and B. Therefore, in an attempt to identify possible donor species, we performed a BLASTn search of the nr database at NCBI using a representative sequence from each group. The best hit for each group was Streptococcus sanguinis (group A) and S. dysgalactiae subsp. equisimilis (group B). Unfortunately, these two species were already included in our phylogeny and were the closest species to each group. Consequently, the likely donor species for these two groups remains unknown.

\section{The role of Lac. 1}

The previous examination of genome sequences for seven human and one bovine sourced isolate showed that in addition to Lac.2, all S. agalactiae isolates possessed 


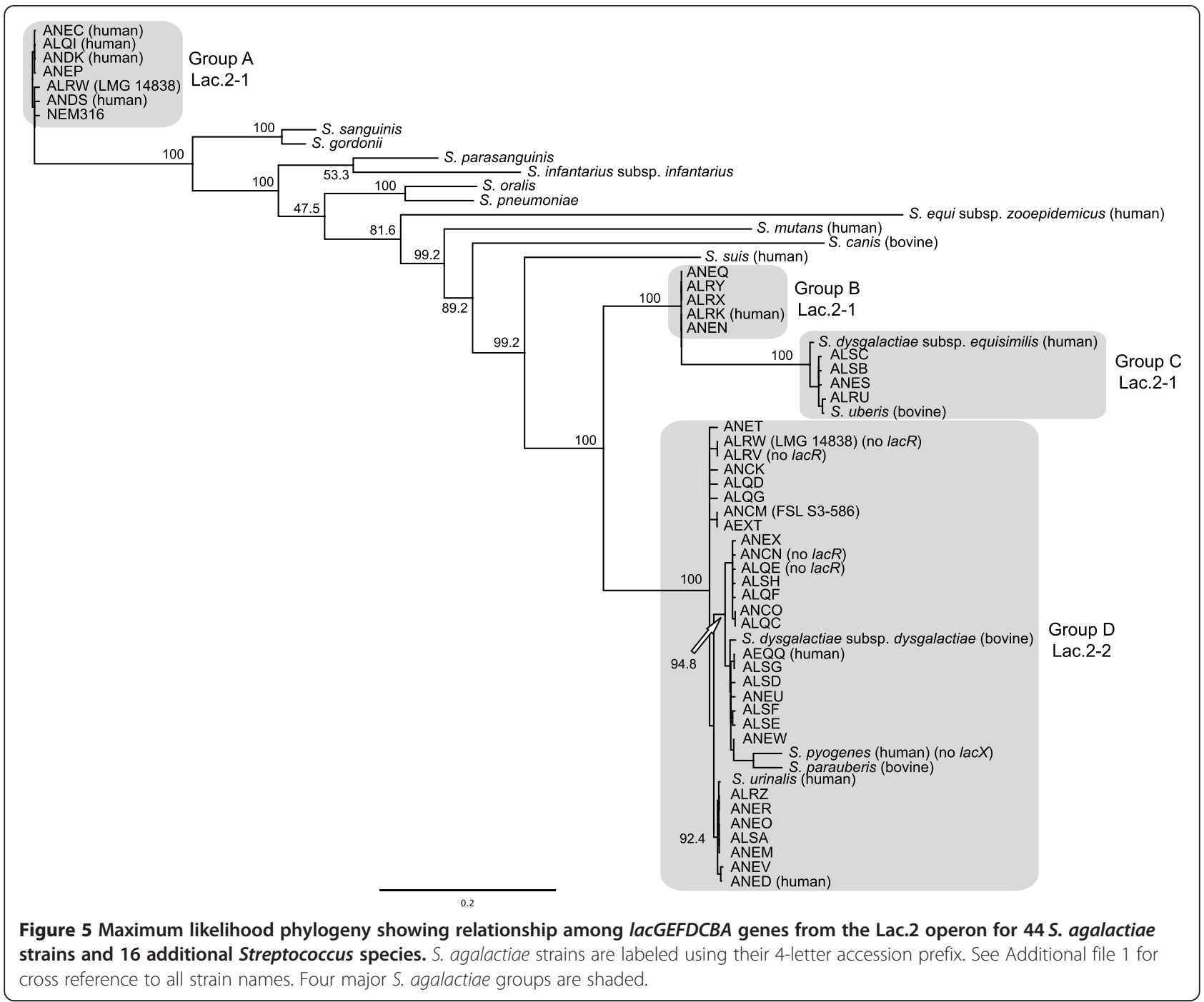

a second lactose operon Lac.1: lacR-IIA-IIB-IIC-neuraminidase- $A B C D X$ [20]. The clustering analysis performed here showed that although genes $A B C D X$ were homologous with those in Lac.2, the operon lacked lacG, a cytoplasmic phospho- $\beta$-galactosidase that hydrolyzes the lactose-6-phosphate produced when lactose is transported into the cell via the PTS. The lactose-6phosphate is hydrolyzed to galactose-6-phosphate prior to it passing through the tagatose-6-phosphate pathway. Consequently, the absence of lacG in Lac.1 suggests that the operon's primary function is not the metabolism of lactose, and Loughman and Caparon [56] suggested a virulent role for the operon in S. pyogenes. Similarly, Lac. 1 in $S$. agalactiae contains neuraminidase, which has been implicated in virulence, also suggesting an alternative role for the operon [64,65]. However, a BLASTn search for lacG in the 202 genome sequences showed it to be present somewhere within the genome of all isolates, raising the possibility that the Lac.1 operon, in concert with lacG, might still play a role in lactose metabolism. However, while the differential expression analysis showed Lac. 1 to be up regulated in milk for the human isolate and NEM316 (Additional file 2), lacG was not upregulated. For the bovine isolate, Lac.1 showed no differential expression, which was likely due to the fact that the operon had been split into two fragments, probably due to insertion sequences that flanked one of the fragments. Similarly, Lac.1 in bovine isolate FSL S3026 was also fragmented by insertion sequences [20]. Using BLASTn we surveyed the 202 genome sequences for the presence of Lac.1. For all isolates, we found the operon to be either contiguous, or its genes to be distributed on two or more contigs. It was contiguous in 150 isolates (human $=120$, bovine $=18$, tilapia $=9$, bullfrog $=1$, grey seal $=1$, dolphin $=1$ ), and distributed on two or more contigs in 51 isolates (human $=31$, bovine $=16$, tilapia $=4$ ). 


\section{Lactose fermentation}

To further investigate the ability of different $S$. agalactiae isolates to metabolize lactose and the roles of Lac.1 and Lac.2, we performed a lactose fermentation test on a set of 124 isolates (Additional file 1). These isolates represented a subset of the 202 isolates whose genome sequences we analyzed earlier, plus the isolates analyzed here using RNAseq data and the bovine isolate FSL S3026 (human $=74$, bovine $=36$, tilapia $=11$, bullfrog $=1$, grey seal $=1$, dolphin $=1$ ). All isolates possessing Lac. 2 showed a positive result for lactose fermentation (media changed to yellow), lending further support to the role of Lac.2 in lactose metabolism. With the exception of three isolates that showed no color change, the media for all remaining isolates changed to orange, suggesting some minimal acid production and fermentation activity. Although showing positive for lactose fermentation, the genome sequence of strain FSL S3-442 lacked Lac.2. We designed a PCR test to investigate whether this was due to a sequencing omission (i.e. this particular region of the genome had not been sequenced). Primers designed within lacF and lacG amplified a $\sim 2.5 \mathrm{kbp}$ region specific to Lac.2 (lacFEG) confirming the operon's presence. Although it's possible that a similar sequencing omission could have occurred in another strain, an omission of this size is likely a rare occurrence.

Overall, our results suggest that the ability to metabolize lactose at a significant level, was acquired via the lateral transfer of the Lac.2 operon and that this was likely an important adaptation to the bovine environment. Furthermore, this mechanism permits rapid adaptation and may explain why some STs suddenly become more prevalent within the bovine environment. For example, the recent rapid increase in the prevalence of ST1, ST-23, and ST-103 in Danish dairy herds [5]. These findings also serve to highlight how attempts to correlate adaptive traits with STs may be misleading (e.g. not all isolates of the same ST possess Lac.2).

Assuming that $S$. agalactiae acquired Lac. 2 within the bovine environment, the isolation of strains from the human environment possessing Lac. 2 highlights the potential for the bovine environment to serve as a reservoir for the emergence of more virulent strains with subsequent transmission to the human population. Furthermore, if LGT is the dominant adaptive process, as also proposed by Sørenson et al. [35], a dependence on MLST as the primary source of molecular epidemiological data will likely prove inadequate for accurate elucidation of these processes. For example, the proposal that the hyperinvasive neonatal ST-17 evolved via vertical inheritance from a bovine ancestor [15] was based on a phylogenetic analysis of ST data. However, more detailed genomic examination has called the accuracy of this relationship into question [12,35], and our results additionally provide no support for this relationship. Specifically, fifteen of the genome sequences surveyed here were ST-17 and none of these isolates possessed Lac.2. Therefore, our results provide no support for ST17 being derived from a bovine adapted strain.

\section{Additional patterns of differential expression}

There were nine genes uniquely up regulated in the bovine isolate (Table 2 and Additional file 3). Two were hypothetical proteins and in general the remainder had roles in binding and membrane transport. One of the genes involved in membrane transport was a coppertransporter ATPase CopA. While essential for life, copper is also highly toxic to cells in excess. The CopA gene product is a copper efflux ATPase involved in copper homeostasis [66,67], and disruption of the gene in Escherichia coli has been shown to produce sensitivity to copper [68]. Copper is present as a trace element in bovine milk $[69,70]$ and up regulation of $\operatorname{Cop} A$ may contribute to extended survival for the bovine isolate within the udder.

In addition to the Lac. 2 genes, there were five up regulated genes shared between the bovine isolate and NEM316 that were not up regulated for the human isolate (Table 2 and Additional file 3). These genes were all involved in metabolic processes, with four of them specifically involved in the metabolism of purine (purC, purF, guaC) and pyrimidine (pyrD). The purine and pyrimidine biosynthetic pathways have been shown to be critical for growth in human blood for other gram positive and negative bacteria [71], and our results show they may also be important for growth in bovine milk. However, Mereghetti et al. [30] found considerably greater expression for these pathways in NEM316 when grown in human blood. Specifically, ten of the 17 genes in the purine pathway and five of the six genes in the pyrimidine pathway were up regulated, suggesting a more important role during growth in blood than milk. In addition, these observations describe a distinctive metabolic contrast for NEM316 when grown in bovine milk compared to human blood. In milk, all of the genes in the Lac. 2 operon were up regulated, whereas only four genes in the purine and pyrimidine biosynthetic pathways were up regulated. In contrast, growth in blood resulted in up regulation of all the genes in the purine and pyrimidine pathways and just two in Lac.2 ( $l a c D$ and lacE) [30]. These observations reveal a metabolic flexibility for NEM316, where the strain can up or down regulate different metabolic pathways to various levels of expression depending on the environment.

The fifth of the up regulated genes shared between the bovine isolate and NEM316 was a GCN5-related Nacetyltransferase (GNAT). An important activity of some members of this family of genes is antibiotic 
Table 2 Uniquely up regulated genes for S. agalactiae strains NEM316 and FSL S3-586

\begin{tabular}{|c|c|c|c|}
\hline Strain & Locus tag & Gene & Sequence description \\
\hline FSL S3-586 ${ }^{\mathrm{A}}$ & FSLS3586_00500 & & Family transcriptional regulator \\
\hline FSL S3-586 ${ }^{\mathrm{A}}$ & FSLS3586_01665 & & Xanthine uracil permease family protein \\
\hline FSL S3-586 ${ }^{\mathrm{A}}$ & FSLS3586_04875 & & 23S rRNA (uracil-5-)-methyltransferase \\
\hline FSL S3-586 ${ }^{\mathrm{A}}$ & FSLS3586_07316 & & Conjugal transfer protein \\
\hline FSL S3-586 ${ }^{\mathrm{A}}$ & FSLS3586_07998 & & Cyclic nucleotide-binding domain protein \\
\hline FSL S3-586 ${ }^{\mathrm{A}}$ & FSLS3586_08765 & Xers & Site-specific tyrosine recombinase \\
\hline FSL S3-586 ${ }^{\mathrm{A}}$ & FSLS3586_09285 & & Hypothetical protein \\
\hline FSL S3-586 ${ }^{\mathrm{A}}$ & FSLS3586_09582 & & Hypothetical protein \\
\hline FSL S3-586 ${ }^{\mathrm{A}}$ & FSLS3586_10962 & CopA & Copper-translocating P-type ATPase \\
\hline FSL S3-586 ${ }^{\mathrm{B}}$ & FSLS3586_02692 & lacG & 6-phospho-beta-galactosidase \\
\hline NEM316 $6^{B}$ & gbs1329 & lacG & 6-phospho-beta-galactosidase \\
\hline FSL S3-586 ${ }^{\mathrm{B}}$ & FSLS3586_05359 & pyrD & Dihydroorotate dehydrogenase $1 \mathrm{~A}$ \\
\hline NEM $316^{B}$ & gbs0553 & pyrD & Dihydroorotate dehydrogenase $1 \mathrm{~A}$ \\
\hline FSL S3-586 ${ }^{\mathrm{B}}$ & FSLS3586_10188 & guac & Guanosine 5-monophosphate oxidoreductase \\
\hline NEM $316^{B}$ & gbs1154 & guaC & Guanosine 5-monophosphate oxidoreductase \\
\hline FSL S3-586 ${ }^{\mathrm{B}}$ & FSLS3586_09702 & purF & Amidophosphoribosyltransferase \\
\hline NEM316 ${ }^{\mathrm{B}}$ & gbs0025 & purF & Amidophosphoribosyltransferase \\
\hline FSL S3-586 & FSLS3586_09687 & & GNAT family acetyltransferase \\
\hline NEM $316^{B}$ & gbs0028 & & GNAT family acetyltransferase \\
\hline FSL S3-586 ${ }^{B}$ & FSLS3586_09712 & purC & Phosphoribosylaminoimidazole-succinocarboxamide synthase \\
\hline NEM316 ${ }^{B}$ & gbs0023 & purC & Phosphoribosylaminoimidazole-succinocarboxamide synthase \\
\hline FSL S3-586 ${ }^{\mathrm{B}}$ & FSLS3586_02702 & lacF & PTS lactose-specific IIA component \\
\hline NEM316 ${ }^{B}$ & gbs1331 & lacF & Lactose-specific phosphotransferase enzyme IIA component \\
\hline FSL S3-586 ${ }^{B}$ & FSLS3586_02697 & lacE & PTS lactose-specific iibc component \\
\hline NEM316 ${ }^{\mathrm{B}}$ & gbs1330 & lacE & PTS family lactose porter iicb component \\
\hline NEM316 ${ }^{C}$ & gbs0668 & & D-lactate dehydrogenase \\
\hline NEM316 ${ }^{\mathrm{C}}$ & gbs0789 & & Major facilitator superfamily protein \\
\hline NEM316 ${ }^{\mathrm{C}}$ & gbs1264 & & Alpha-acetolactate decarboxylase \\
\hline NEM316 ${ }^{\mathrm{C}}$ & gbs1332 & lact & Transcription antiterminator \\
\hline NEM $316^{\mathrm{C}}$ & gbs1508 & & 4-alpha-glucanotransferase \\
\hline NEM $316^{\mathrm{C}}$ & gbs1619 & & D-3-phosphoglycerate dehydrogenase \\
\hline NEM316 ${ }^{C}$ & gbs1627 & & CBS domain protein \\
\hline NEM316 ${ }^{C}$ & gbs1630 & & Branched-chain amino acid ABC superfamily ATP binding cassette permease protein \\
\hline NEM316 ${ }^{C}$ & gbs1631 & & Branched-chain amino acid ABC superfamily ATP binding cassette membrane protein \\
\hline NEM316 & gbs1632 & & Branched-chain amino acid $A B C$ amino acid-binding protein \\
\hline NEM316 & gbs2002 & & Glycerol dehydrogenase \\
\hline
\end{tabular}

Superscript $A=$ genes uniquely up regulated for FSL S3-586, superscript $B=$ genes uniquely up regulated for FSL S3-586 and NEM316, superscript $C=$ genes uniquely up regulated for NEM316.

(aminoglycoside) resistance [72,73]. To explore the gene's role in $S$. agalactiae further, we performed a BLASTn search of the nr database at NCBI using the NEM316 nucleotide sequence. The top five hits were for $S$. agalactiae strains, with each hit having a similar gene annotation to NEM316. However, the next best hit was for a Zwittermicin A resistance protein zmaR from Lactobacillus salivarius (72\% identity, 44\% coverage), lending support to the possibility that the $S$. agalactiae GNAT gene may also be involved in antibiotic resistance. S. agalactiae infection is frequently treated with antibiotics [9]. Furthermore, blanket dry cow therapy (infusion of the udder with antibiotics during the dry period as a mastitis preventative measure) is now 
common place within the US dairy industry [74]. A commonly used antibiotic is penicillin-dihydrostreptomycin (Quartermaster; Pfizer Animal Health) [74] and dihydrostreptomycin is an aminoglycoside antibiotic. Consequently, up regulation of the putative antibiotic resistance gene might reflect an adaptation to this type of treatment where growth in milk elicits high expression of the gene for bovine adapted strains. Indeed, Brown and Scasserra [75] reported low susceptibility to streptomycin for $S$. agalactiae isolated from bovine mammary glands. An alternative explanation for up regulation of the gene is the presence of an antibiotic in the milk sample. This seems unlikely as none of the four cows providing the milk were treated with antibiotics for six months prior to milk collection. Regardless, the potential role of this gene in antibiotic resistance remains preliminary without further functional analyses.

For NEM316, there were 11 uniquely up regulated genes (Table 2 and Additional file 3). In general, these genes had roles in oxidation-reduction processes and membrane transport. One of these genes was a glycerol dehydrogenase. These enzymes are utilized in the metabolism of glycerol, which bacteria can use as a carbon source in anaerobic conditions through coupled oxidative and reductive pathways [76-78]. The triglycerides in bovine milk contain glycerol and the up regulation of glycerol dehydrogenase for NEM316 suggests that the isolate might be utilizing glycerol as a carbon source. Furthermore, glycerol-catabolizing enzymes have been shown to be important for bacterial growth [79] and NEM316 showed considerably more growth in milk than the other two isolates (Figure 1). An additional up regulated dehydrogenase was D-lactate dehydrogenase. Lactose is composed of $\beta$-D-galactose and $\alpha / \beta$-D-glucose. After transport of lactose into the cell via the PTS, lacG hydrolyzes lactose-6-phosphate into both galactose-6phosphate and glucose [80] (galactose-6-phosphate is passed to the tagatose pathway [Lac.2] as discussed above). The final product of the glycolysis of glucose is pyruvate, and when oxygen is absent or in short supply, D-lactate dehydrogenase converts pyruvate to lactate [81]. Consequently, up regulation of D-lactate dehydrogenase suggests active metabolism of the glucose component of lactose for NEM316. Glucose metabolism is also indicated by the up regulation of $\alpha$-acetolactate decarboxylase, which is involved in the anabolism of acetoin from pyruvate [82]. This gene activity might again contribute to strain NEM316's stronger growth in milk.

\section{Nisin and insertion sequences}

Streptococcus uberis possesses an 11-gene operon for the production of the lantibiotic nisin [83]. The operon is part of the species' dispensable genome, [83] and Pryor et al. [84] showed that nisin producer strains dominated non-producer strains during intramammary infection, suggesting a competitive advantage. S. agalactiae (stain FSL S3-026) also possesses the operon [20]. However, the operon is disrupted by an insertion sequence (IS) and a deferred antagonism test showed the strain to not produce nisin. The bovine $S$. agalactiae isolate studied here (strain FSL S3-586) also possessed the operon; but again the operon was disrupted by insertion sequences (fragmented into two). However, all 11 operon genes showed some expression in milk, whereas only five showed expression in broth. However, this expression was not significantly different between the two environments and a previous deferred antagonism test showed the strain to not produce nisin [20]. Similar to strain FSL S3-026, strain FSL S3-586 also possessed numerous insertion sequences (122) throughout its genome, lending further support to the importance of IS activity in the evolution of S. agalactiae. A total of 106 (86.9\%) of the 122 IS showed no gene expression in either milk or broth, while 12 IS were expressed in both environments, although not differentially, suggesting some IS activity in both environments. Four IS showed negligible expression in milk only. The human isolate contained considerably fewer IS (42). However, there was a similar number of IS showing expression in both environments (11). The lower number of IS for human isolates may be typical, as the average number of IS for the human $S$. agalactiae isolates $2603 \mathrm{~V} / \mathrm{R}, \mathrm{H} 36 \mathrm{~B}, 18 \mathrm{RS} 21, \mathrm{~A} 909,515$, CJB111, and COH1 was 23 [20]. NEM316 is somewhat distinctive in that it possesses a comparatively very low number of IS (5), with three showing expression in both environments. The high number of IS for the bovine isolates might reflect a degree of specialization to this environment. For example, several studies have suggested that proliferation of insertion sequences is an evolutionary signature that accompanies the transition to a more specialized life style [85-88]. Specifically, in any population, the transposition of IS into genes occurs at a particular rate, and in large populations, if a transposition is lethal or results in a selective disadvantage, the bacterial will be removed from the population via purifying selection. However, the reduction in population size that typically accompanies specialization increases the effect of genetic drift, which is now able to fix more of the deleterious transpositions into the population. The very low number of IS for NEM316 might reflect a larger population size associated with a more generalist ability (ST-23 has the widest reported host distribution).

\section{Conclusion}

Our study detected numerous genetic factors likely important in S. agalactiae's adaptation to the bovine environment. In particular, the acquisition of Lac. 2 and the ability to efficiently metabolize lactose appears to have 
been a major adaptation. We provide convincing evidence supporting LGT as the mechanism responsible for this adaptation, and rather than being a single evolutionary event, it appears to have occurred multiple times, with all Streptococcus species known to be major causes of mastitis identified as possible donors. This process has resulted in genetically divergent types of Lac.2 within S. agalatiae warranting further investigation into the possible affects this has on survivability and the propensity to cause mastitis. Other factors such as up regulation of genes involved in copper homeostasis, and metabolism of purine, pyrimidine, glycerol and glucose were also specific to bovine adapted strains. Although somewhat speculative without further functional studies, the up regulation of a GNAT gene during growth in milk that may impart antibiotic resistance, was of particular interest, as it hinted at an adaptation to the use of antibiotics within this environment. Other mastitis causing pathogens are less responsive to antibiotics [10] and the evidence provided here and elsewhere, for LGT between S. agalactiae and these species, highlights the potential for further development and spread of antibiotic resistance.

\section{Availability of supporting data}

The Illumina derived short read files are available at the NCBI Sequence Read Archive (SRA) under the study accession number SRP026339.

\section{Additional files}

\section{Additional file 1: Strain information. \\ Additional file 2: Results of differential expression analysis and} GO terms.

Additional file 3: Uniquely up regulated genes for NEM316 and FSL S3-586.

\section{Competing interests}

The authors declare that they have no competing interests.

\section{Authors' contributions}

VPR and MJS conceived the project; VPR conducted data analysis and wrote the manuscript; MJS provided the conceptual framework, helped write the manuscript, and secured funding; MJS and PDPB provided experimental design; SCC designed and implemented the RNAseq analysis pipeline; PDPB conducted laboratory work associated with bacteria culturing, lactose fermentation, and transcriptome sequencing; AAG provided milk samples and helped design laboratory protocols. All authors read and approved the final manuscript.

\section{Acknowledgements}

This work was supported by the National Institute of Allergy and Infectious Disease, U.S. National Institutes of Health, under grant number Al073368, awarded to MJS

\section{Author details}

${ }^{1}$ Department of Population Medicine and Diagnostic Sciences, College of Veterinary Medicine, Cornell University, Ithaca, NY 14853, USA. ${ }^{2}$ Department of Biological Statistics and Computational Biology, Cornell University, Ithaca, NY 14853, USA. ${ }^{3}$ Current address: Institute of Arctic Biology, University of
Alaska Fairbanks, Fairbanks, AK 99775, USA. ${ }^{4}$ Current address: Merck Animal Health, Global Ruminants Business Unit, Summit, NJ 07901, USA.

Received: 1 July 2013 Accepted: 21 December 2013

Published: 27 December 2013

References

1. Baker C: Group B streptococcal infections. In Streptococcal infections Clinical aspects, microbiology, and molecular pathogenesis. Edited by Stevens D, Kaplan E. New York: Oxford Univeristy Press; 2000:222-237.

2. Balter S, Whitney C, Schuchat A: Epidemiology of group B streptococcal infections. In Gram-positive pathogens. Edited by Fischetti V, Novick R, Ferreti J, Portnoy D, Rood J. Washington, D.C: ASM Press; 2000

3. Dermer P, Lee C, Eggert J, Few B: A history of neonatal group B streptococcus with its related morbidity and mortality rates in the United States. J Pediatr Nurs 2004, 19(5):357-363.

4. Zadoks R, Fitzpatrick J: Changing trends in mastitis. Irish Vet J 2009, 62S:59-70

5. Zadoks RN, Middleton JR, McDougall S, Katholm J, Schukken YH: Molecular epidemiology of mastitis pathogens of dairy cattle and comparative relevance to humans. J Mammary Gland Biol Neoplasia 2011, 16(4):357-372.

6. Heikkila AM, Nousiainen $\mathrm{J}$, Pyorala S: Costs of clinical mastitis with special reference to premature culling. J Dairy Sci 2012, 95(1):139-150.

7. Hogeveen $\mathrm{H}$, Huijps $\mathrm{K}$, Lam TJ: Economic aspects of mastitis: new developments. N Z Vet J 2011, 59(1):16-23.

8. Bramley AJ, Cullor JS, Erskine RJ, Fox LK, Harmon RJ, Hogan JS, Nickerson SC, Oliver SP, Smith KL, Sordillo LM: Current Concepts in Bovine Mastitis. 4th edition. Madison, Wl: National Mastitis Council; 1996.

9. Keefe GP: Streptococcus agalactiae mastitis: a review. Can Vet J 1997, 38(7):429-437.

10. Wilson DJ, Gonzalez RN, Case KL, Garrison LL, Grohn YT: Comparison of seven antibiotic treatments with no treatment for bacteriological efficacy against bovine mastitis pathogens. J Dairy Sci 1999, 82(8):1664-1670.

11. Katholm J, Rattenborg E: The surviellance program of Streptococcus agalactiae in Danish dairy herds 1989-2008. In Proceedings of the 5th IDF Mastitis Conference: Mastitis Research into Practice: 2010. Christchurch, New Zealand: New Zealand Veterinary Association, Vet Learn; 2010:241-246.

12. Brochet M, Couve E, Zouine M, Vallaeys T, Rusniok C, Lamy MC, Buchrieser C, Trieu-Cuot P, Kunst F, Poyart C, et al: Genomic diversity and evolution within the species Streptococcus agalactiae. Microbes Infect 2006, 8(5):1227-1243.

13. Bishop EJ, Shilton C, Benedict S, Kong F, Gilbert GL, Gal D, Godoy D, Spratt BG, Currie BJ: Necrotizing fasciitis in captive juvenile Crocodylus porosus caused by Streptococcus agalactiae: an outbreak and review of the animal and human literature. Epidemiol Infect 2007, 135(8):1248-1255.

14. Evans JJ, Bohnsack JF, Klesius PH, Whiting AA, Garcia JC, Shoemaker CA, Takahashi S: Phylogenetic relationships among Streptococcus agalactiae isolated from piscine, dolphin, bovine and human sources: a dolphin and piscine lineage associated with a fish epidemic in Kuwait is also associated with human neonatal infections in Japan. J Med Microbiol 2008, 57(Pt 11):1369-1376.

15. Bisharat N, Crook DW, Leigh J, Harding RM, Ward PN, Coffey TJ, Maiden MC, Peto $\mathrm{T}$, Jones N: Hyperinvasive neonatal group B streptococcus has arisen from a bovine ancestor. J Clin Microbiol 2004, 42(5):2161-2167.

16. Bohnsack JF, Whiting AA, Martinez G, Jones N, Adderson EE, Detrick S, Blaschke-Bonkowsky AJ, Bisharat N, Gottschalk M: Serotype III Streptococcus agalactiae from bovine milk and human neonatal infections. Emerg Infect Dis 2004, 10(8):1412-1419.

17. Dogan B, Schukken YH, Santisteban C, Boor KJ: Distribution of serotypes and antimicrobial resistance genes among Streptococcus agalactiae isolates from bovine and human hosts. J Clin Microbiol 2005, 43(12):5899-5906.

18. Sukhnanand S, Dogan B, Ayodele MO, Zadoks RN, Craver MP, Dumas NB, Schukken YH, Boor KJ, Wiedmann M: Molecular subtyping and characterization of bovine and human Streptococcus agalactiae isolates. J Clin Microbiol 2005, 43(3):1177-1186.

19. Martinez G, Harel J, Higgins R, Lacouture S, Daignault D, Gottschalk M: Characterization of Streptococcus agalactiae isolates of bovine and human origin by randomly amplified polymorphic DNA analysis. J Clin Microbiol 2000, 38(1):71-78. 
20. Richards VP, Lang P, Bitar PD, Lefebure $T$, Schukken $Y H$, Zadoks RN, Stanhope MJ: Comparative genomics and the role of lateral gene transfer in the evolution of bovine adapted Streptococcus agalactiae. Infect Genet Evol 2011, 11(6):1263-1275.

21. Tettelin H, Masignani V, Cieslewicz MJ, Donati C, Medini D, Ward NL, Angiuoli SV, Crabtree J, Jones AL, Durkin AS, et al: Genome analysis of multiple pathogenic isolates of Streptococcus agalactiae: implications for the microbial "pan-genome". Proc Natl Acad Sci U S A 2005, 102(39):13950-13955.

22. Cornejo OE, Lefebure T, Pavinski Bitar PD, Lang P, Richards VP, Eilertson K, Do T, Beighton D, Zeng L, Ahn SJ, et al: Evolutionary and population genomics of the cavity causing bacteria Streptococcus mutans. Mol Biol Evol 2013, 30(4):881-893.

23. Lefebure T, Stanhope MJ: Evolution of the core and pan-genome of Streptococcus: positive selection, recombination, and genome composition. Genome Biol 2007, 8(5):R71.

24. Marri PR, Hao W, Golding GB: The role of laterally transferred genes in adaptive evolution. BMC Evol Biol 2007, 7(Suppl 1):S8.

25. Marri PR, Hao W, Golding GB: Gene gain and gene loss in streptococcus: is it driven by habitat? Mol Biol Evol 2006, 23(12):2379-2391.

26. Hao W, Golding GB: Patterns of bacterial gene movement. Mol Biol Evol 2004, 21(7):1294-1307.

27. Hao W, Golding GB: The fate of laterally transferred genes: life in the fast lane to adaptation or death. Genome Res 2006, 16(5):636-643.

28. Kamneva OK, Knight SJ, Liberles DA, Ward NL: Analysis of genome content evolution in pvc bacterial super-phylum: assessment of candidate genes associated with cellular organization and lifestyle. Genome Biol Evol 2012, 4(12):1375-1390.

29. Mereghetti L, Sitkiewicz I, Green NM, Musser JM: Extensive adaptive changes occur in the transcriptome of Streptococcus agalactiae (group B streptococcus) in response to incubation with human blood. PLoS One 2008, 3(9):e3143.

30. Mereghetti L, Sitkiewicz I, Green NM, Musser JM: Remodeling of the Streptococcus agalactiae transcriptome in response to growth temperature. PLoS One 2008, 3(7):e2785.

31. Mereghetti L, Sitkiewicz I, Green NM, Musser JM: Identification of an unusual pattern of global gene expression in group B Streptococcus grown in human blood. PLoS One 2009, 4(9):e7145.

32. Sitkiewicz I, Green NM, Guo N, Bongiovanni AM, Witkin SS, Musser JM: Transcriptome adaptation of group B Streptococcus to growth in human amniotic fluid. PLoS One 2009, 4(7):e6114.

33. Sitkiewicz I, Musser JM: Analysis of growth-phase regulated genes in Streptococcus agalactiae by global transcript profiling. BMC Microbiol 2009, 9:32.

34. Manning SD, Springman AC, Lehotzky E, Lewis MA, Whittam TS, Davies HD Multilocus sequence types associated with neonatal group $B$ streptococcal sepsis and meningitis in Canada. J Clin Microbiol 2009, 47(4):1143-1148.

35. Sørensen UB, Poulsen K, Ghezzo C, Margarit I, Kilian M: Emergence and global dissemination of host-specific Streptococcus agalactiae Clones. MBio 2010, 1(3):e00178-00110.

36. Jones N, Bohnsack JF, Takahashi S, Oliver KA, Chan MS, Kunst F, Glaser P, Rusniok C, Crook DW, Harding RM, et al: Multilocus sequence typing system for group B streptococcus. J Clin Microbiol 2003, 41(6):2530-2536.

37. Glaser P, Rusniok C, Buchrieser C, Chevalier F, Frangeul L, Msadek T, Zouine M, Couve E, Lalioui L, Poyart C, et al: Genome sequence of Streptococcus agalactiae, a pathogen causing invasive neonatal disease. Mol Microbiol 2002, 45(6):1499-1513.

38. Florindo C, Ferreira R, Borges V, Spellerberg B, Gomes JP, Borrego MJ: Selection of reference genes for real-time expression studies in Streptococcus agalactiae. J Microbiol Methods 2012, 90(3):220-227.

39. Oliveira L, Madureira P, Andrade EB, Bouaboud A, Morello E, Ferreira P, Poyart C, Trieu-Cuot P, Dramsi S: Group B streptococcus GAPDH is released upon cell lysis, associates with bacterial surface, and induces apoptosis in murine macrophages. PLoS One 2012, 7(1):e29963.

40. Herigstad B, Hamilton M, Heersink J: How to optimize the drop plate method for enumerating bacteria. J Microbio/ Methods 2001, 44(2):121-129.

41. Martin M: Cutadapt removes adapter sequences from high-throughput sequencing reads. EMBnetjournal 2011, 17(1):10-12.

42. Li H, Durbin R: Fast and accurate short read alignment with BurrowsWheeler transform. Bioinformatics 2009, 25(14):1754-1760.
43. Li H, Handsaker B, Wysoker A, Fennell T, Ruan J, Homer N, Marth G, Abecasis $\mathrm{G}$, Durbin R: The sequence alignment/map format and SAMtools. Bioinformatics 2009, 25(16):2078-2079.

44. Dessau RB, Pipper CB: "R"-project for statistical computing. Ugeskr Laeger 2008, 170(5):328-330.

45. Anders S, Huber W: Differential expression analysis for sequence count data. Genome Biol 2010, 11(10):R106.

46. Benjamini $Y$, Hochberg $Y$ : Controlling the false discovery rate: a practical and powerful approach to multiple testing. J Royal Stat Soc Ser B 1995, 57:289-300.

47. Gotz S, Garcia-Gomez JM, Terol J, Williams TD, Nagaraj SH, Nueda MJ, Robles M, Talon M, Dopazo J, Conesa A: High-throughput functional annotation and data mining with the Blast2GO suite. Nucleic Acids Res 2008, 36(10):3420-3435.

48. Van Dongen S: Graph clustering by flow simulation. University of Utrecht: PhD thesis; 2000.

49. Brohee $S$, Van Helden J: Evaluation of clustering algorithms for proteinprotein interaction networks. BMC Bioinformatics 2006, 7:488.

50. Katoh K, Misawa K, Kuma K, Miyata T: MAFFT: a novel method for rapid multiple sequence alignment based on fast Fourier transform. Nucleic Acids Res 2002, 30(14):3059-3066.

51. Drummond A, Ashton B, Buxton S, Cheung M, Cooper A, Heled J, Kearse M, Moir R, Stones-Havas S: Geneious v5.1. 2010. Available from http://www. geneious.com.

52. Guindon S, Dufayard JF, Lefort V, Anisimova M, Hordijk W, Gascuel O: New algorithms and methods to estimate maximum-likelihood phylogenies: assessing the performance of PhyML 3.0. Syst Biol 2010, 59(3):307-321.

53. Posada D, Crandall KA: MODELTEST: testing the model of DNA substitution. Bioinformatics 1998, 14(9):817-818.

54. Zeng L, Das S, Burne RA: Utilization of lactose and galactose by Streptococcus mutans: transport, toxicity, and carbon catabolite repression. J Bacteriol 2010, 192(9):2434-2444.

55. Ferretti JJ, McShan WM, Ajdic D, Savic DJ, Savic G, Lyon K, Primeaux C, Sezate S, Suvorov AN, Kenton S, et al: Complete genome sequence of an M1 strain of Streptococcus pyogenes. Proc Natl Acad Sci U S A 2001 98(8):4658-4663.

56. Loughman JA, Caparon MG: Comparative functional analysis of the lac operons in Streptococcus pyogenes. Mol Microbiol 2007, 64(2):269-280.

57. vanRooijen RJ, Dechering KJ, Niek C, Wilmink J, De Vos WM: Lysines 72, 80 and 213 and aspartic acid 210 of the Lactococcus lactis LacR repressor are involved in the response to the inducer tagatose-6-phosphate leading to induction of lac operon expression. Protein Eng 1993, 6(2):201-206.

58. Alpert CA, Siebers U: The lac operon of Lactobacillus casei contains lacT, a gene coding for a protein of the Bg1G family of transcriptional antiterminators. J Bacterio/ 1997, 179(5):1555-1562.

59. Brown GD, Thomson JA: Isolation and characterisation of an aryl-beta-Dglucoside uptake and utilisation system (abg) from the gram-positive ruminal Clostridium species C. longisporum. Mol Gen Genet 1998, 257(2):213-218.

60. Cote CK, Honeyman AL: The LicT protein acts as both a positive and a negative regulator of loci within the bgl regulon of Streptococcus mutans. Microbiology 2003, 149(Pt 5):1333-1340.

61. Springman AC, Lacher DW, Wu G, Milton N, Whittam TS, Davies HD Manning SD: Selection, recombination, and virulence gene diversity among group B streptococcal genotypes. J Bacteriol 2009, 191(17):5419-5427.

62. Richards VP, Zadoks RN, Pavinski Bitar PD, Lefebure T, Lang P, Werner B, Tikofsky L, Moroni P, Stanhope MJ: Genome characterization and population genetic structure of the zoonotic pathogen, Streptococcus canis. BMC Microbiol 2012, 12:293

63. Tikofsky LL, Zadoks RN: Cross-infection between cats and cows: origin and control of Streptococcus canis mastitis in a dairy herd. J Dairy Sci 2005, 88(8):2707-2713.

64. Tong $H H$, Blue LE, James MA, DeMaria TF: Evaluation of the virulence of a Streptococcus pneumoniae neuraminidase-deficient mutant in nasopharyngeal colonization and development of otitis media in the chinchilla model. Infect Immun 2000, 68(2):921-924.

65. Soong G, Muir A, Gomez MI, Waks J, Reddy B, Planet P, Singh PK, Kaneko Y, Wolfgang MC, Hsiao YS, et al: Bacterial neuraminidase facilitates mucosal infection by participating in biofilm production. J Clin Invest 2006, 116(8):2297-2305. 
66. Osman D, Cavet JS: Copper homeostasis in bacteria. Adv App/ Microbiol 2008, 65:217-247.

67. Solioz M, Abicht HK, Mermod M, Mancini S: Response of gram-positive bacteria to copper stress. J Biol Inorg Chem 2010, 15(1):3-14.

68. Rensing C, Fan B, Sharma R, Mitra B, Rosen BP: CopA: an Escherichia coli Cu (I)-translocating P-type ATPase. Proc Natl Acad Sci U S A 2000, 97(2):652-656

69. Supplee G, Bellis B: The copper content of cow's milk. J Dairy Sci 1922, 5:455-467.

70. Lonnerdal B, Keen CL, Hurley LS: Iron, copper, zinc, and manganese in milk. Annu Rev Nutr 1981, 1:149-174.

71. Samant S, Lee H, Ghassemi M, Chen J, Cook JL, Mankin AS, Neyfakh AA: Nucleotide biosynthesis is critical for growth of bacteria in human blood. PLoS Pathog 2008, 4(2):e37.

72. Vetting MW, SdC LP, Yu M, Hegde SS, Magnet S, Roderick SL, Blanchard JS: Structure and functions of the GNAT superfamily of acetyltransferases. Arch Biochem Biophys 2005, 433(1):212-226.

73. Dyda F, Klein DC, Hickman AB: GCN5-related N-acetyltransferases: a structural overview. Annu Rev Biophys Biomol Struct 2000, 29:81-103.

74. Arruda AG, Godden S, Rapnicki P, Gorden P, Timms L, Aly SS, Lehenbauer TW, Champagne J: Randomized noninferiority clinical trial evaluating 3 commercial dry cow mastitis preparations: I: quarter-level outcomes. J Dairy Sci 2013.

75. Brown MB, Scasserra AE: Antimicrobial resistance in streptococcal species isolated from bovine mammary glands. Am J Vet Res 1990, 51(12):2015-2018.

76. Ruzheinikov SN, Burke J, Sedelnikova S, Baker PJ, Taylor R, Bullough PA, Muir NM, Gore MG, Rice DW DW: Glycerol dehydrogenase structure, specificity, and mechanism of a family III polyol dehydrogenase. Structure 2001, 9(9):789-802.

77. Lin EC: Glycerol dissimilation and its regulation in bacteria. Annu Rev Microbiol 1976, 30:535-578.

78. Bizzini A, Zhao C, Budin-Verneuil A, Sauvageot N, Giard JC, Auffray Y, Hartke $A$ : Glycerol is metabolized in a complex and strain-dependent manner in Enterococcus faecalis. J Bacteriol 2010, 192(3):779-785.

79. Joseph B, Przybilla K, Stuhler C, Schauer K, Slaghuis J, Fuchs TM, Goebel W: Identification of Listeria monocytogenes genes contributing to intracellular replication by expression profiling and mutant screening J Bacteriol 2006, 188(2):556-568.

80. De Vos WM, Vaughan EE: Genetics of lactose utilization in lactic acid bacteria. FEMS Microbiol Rev 1994, 15(2-3):217-237.

81. Garvie El: Bacterial lactate dehydrogenases. Microbiol Rev 1980 44(1):106-139.

82. Xiao Z, Xu P: Acetoin metabolism in bacteria. Crit Rev Microbiol 2007, 33(2):127-140

83. Wirawan RE, Klesse NA, Jack RW, Tagg JR: Molecular and genetic characterization of a novel nisin variant produced by Streptococcus uberis. Appl Environ Microbiol 2006, 72(2):1148-1156.

84. Pryor SM, Cursons RT, Williamson JH, Lacy-Hulbert SJ: Experimentally induced intramammary infection with multiple strains of Streptococcus uberis. J Dairy Sci 2009, 92(11):5467-5475.

85. Parkhill J, Sebaihia M, Preston A, Murphy LD, Thomson N, Harris DE, Holden MT, Churcher CM, Bentley SD, Mungall KL, et al: Comparative analysis of the genome sequences of Bordetella pertussis, Bordetella parapertussis and Bordetella bronchiseptica. Nat Genet 2003, 35(1):32-40.

86. Song H, Hwang J, Yi H, Ulrich RL, Yu Y, Nierman WC, Kim HS: The early stage of bacterial genome-reductive evolution in the host. PLOS Pathog 2010, 6(5):e1000922

87. Siguier $\mathrm{P}$, Filee J, Chandler M: Insertion sequences in prokaryotic genomes. Curr Opin Microbiol 2006, 9(5):526-531.

88. Moran NA, Plague GR: Genomic changes following host restriction in bacteria. Curr Opin Genet Dev 2004, 14(6):627-633.

doi:10.1186/1471-2164-14-920

Cite this article as: Richards et al.: Transcriptomic and genomic evidence for Streptococcus agalactiae adaptation to the bovine environment. BMC Genomics 2013 14:920.

\section{Submit your next manuscript to BioMed Central and take full advantage of:}

- Convenient online submission

- Thorough peer review

- No space constraints or color figure charges

- Immediate publication on acceptance

- Inclusion in PubMed, CAS, Scopus and Google Scholar

- Research which is freely available for redistribution

Submit your manuscript at www.biomedcentral.com/submit
C) Biomed Central 